\title{
ESTUDO COMPARATIVO DA TEMPERATURA DE PREPARAÇÕES SERVIDAS EM DUAS UANs DISTINTAS
}

\author{
Bárbara Letícia Dias da Silva Nascimento ${ }^{1}$ \\ Fernanda Santos Leal ${ }^{2}$ \\ Renata Quartieri Nascimento ${ }^{3}$
}

RESUMO: Este estudo tem como objetivo confirmar a importância do controle da temperatura, sobretudo das preparações frias em duas UANs distintas: uma do tipo institucional, servindo funcionários de uma indústria, e a outra do tipo comercial, sendo um restaurante popular. Durante 14 dias foram avaliadas, e comparadas, as temperaturas aferidas ao meio dia dos dois tipos de saladas servidas em cada UAN. De acordo os critérios do artigo 47 da Portaria CVS 5/2013, a maioria das temperaturas se apresentou irregular, sendo as do restaurante popular as mais inadequadas devido à grande demanda. A fim de melhorar o controle das temperaturas que foram encontradas fora do regulamento, conclui-se que a quantidade de preparações em cubas deve ser ajustada de forma que o resfriamento pós-preparo seja completo e proporcional. Consequentemente, necessita-se adequar a utilização e a temperatura dos equipamentos durante a espera até a distribuição para atender as boas práticas e a legislação que garantem a segurança alimentar.

Palavras-chave: Temperatura. Preparações frias. Saladas. Boas práticas. Segurança alimenta.

\section{INTRODUÇÃO}

As refeições coletivas suprem cada vez mais as necessidades da vida urbana, eliminando assim o deslocamento pela necessidade de refeições saudáveis e seguras da população, sobretudo daqueles que trabalham e estudam distante das suas residências. Dessa forma, há uma crescente demanda pelos serviços de refeição em restaurantes e à qualidade sanitária dos produtos oferecidos configura questão fundamental, pois esses serviços representam locais que têm se destacado na epidemiologia dos surtos de doenças transmitidas por alimentos. (SANTOS, BASSI, 2015).

\footnotetext{
Discente do Curso de Nutrição. Centro Universitário Estácio da Bahia - FIB. Email: nascimento_barbara@hotmail.com.

${ }^{2}$ Discente do Curso de Nutrição. Centro Universitário Estácio da Bahia - FIB.

3 Nutricionista, mestre em ciência de alimentos. Doutoranda em biotecnologia. Docente do Centro Universitário Estácio da Bahia - FIB.
} 
Para que se possa garantir a qualidade higiênico-sanitária nos restaurantes, é preciso que os alimentos comercializados estejam em conformidade com que dispõe as Boas Práticas de Fabricação (BPF), que são normas regulamentares estabelecidas pela Agência Nacional de Vigilância Sanitária (ANVISA).” (SILVA et al., 20ı6).

Uma das formas mais indicadas na literatura para se evitar o crescimento e a consequente proliferação microbiana é por meio do controle do binômio tempo e temperatura. (BORGES et al., 2016).

Sendo assim, o tempo e a temperatura são binômios que devem caminhar juntos, sendo importantes para garantir a segurança do produto e que devem ser monitorados constantemente para manter o alimento na temperatura adequada, auxiliando na prevenção de contaminação e multiplicação microbiana. (SILVA, 2020).

A temperatura favorece o crescimento bacteriano porque está relacionada com a atividade das enzimas dos microrganismos. Todas as enzimas possuem uma temperatura ótima de atuação, que é a energia necessária para ativação dos seus sítios ativos. A temperatura ótima de crescimento de um microrganismo é a temperatura na qual a maioria das suas enzimas está na temperatura ótima de atuação. (GUERRA, 20r6). Levando em conta que a crescente demanda por refeições resulta em uma sobrecarga dos serviços de alimentação, deve-se considerar que o impacto negativo no desempenho dos serviços também contribui para um aumento do risco de doenças transmitidas por alimentos (DTAs). (CONSTANCIO et al., 20I6).

Dentre os fatores que podem justificar o alto percentual de inadequação das temperaturas das preparações quentes e frias estão: a temperatura inadequada do balcão térmico, as cubas com excesso de alimentos, elevado tempo de exposição do alimento e o armazenamento incorreto na fase pós preparo. (PEREIRA et al, 2019).

Destacando-se as saladas por serem consideradas potencialmente perigosas e propiciarem a multiplicação microbiana, por exemplo, deve-se assegurar que estejam mantidas no balcão de distribuição por até quatro horas quando em temperatura $<10^{\circ} \mathrm{C}$ após o preparo. (OLIVEIRA et al, 20I2)."

Contudo, para que as preparações sejam servidas em temperaturas adequadas, os equipamentos utilizados para a distribuição e armazenamento dos alimentos prontos para 
o consumo devem possuir um controle rigoroso de temperatura (WIETHÖLTER, FASSINA, 2017).

Nesse sentido faz-se necessário o aperfeiçoamento contínuo das ações de controle sanitário na área de alimentos com objetivo de conter e minimizar os riscos originados pela ingestão de alimentos contaminados. (BARROS, 2019).

A necessidade de confirmar a importância do controle da temperatura, sobretudo das preparações frias, é uma forma de atender as boas práticas e a legislação que garantem a segurança alimentar. Dessa forma, o objetivo deste estudo é avaliar e comparar as temperaturas das saladas servidas em duas UANs distintas, e suas respectivas peculiaridades.

\section{METODOLOGIA}

Trata-se de um estudo de natureza descritiva e transversal, realizado em duas UANs do mesmo grupo de empresa concessionária, uma do tipo institucional, localizada na cidade de Simões Filho - BA, e a outra sendo um restaurante popular, localizada na cidade de Lauro de Freitas - BA.

A UAN institucional presta serviço a uma indústria e serve de 60 a 70 refeições para funcionários diariamente no almoço, das Irhoomin às Izhoomin. A comercial presta serviços à população da cidade, em prédio cedido pela prefeitura, servindo das Irhoomin às I3hzomin, a preço fixo de $\mathrm{R} \$ 2,00$, a quantidade de aproximadamente 1900 refeições diárias. As duas UANs oferecem diariamente, dois tipos de saladas: uma crua e outra cozida.

Foram utilizados como amostra, os formulários apresentados aqui no anexo A, que registram as temperaturas aferidas às I2hoomin ( 2 horas e meia após o preparo) nas unidades.

Como instrumentos de coleta, além dos formulários mencionados acima, foi utilizado o termômetro de marca AKo5, que é digital, de espeto e à prova d'água. Para evitar contaminação entre os alimentos, o termômetro foi esterilizado com pano de limpeza novo da marca "Perfex" e álcool 70\% antes e após as aferições.

Foi observado também, a utilização dos equipamentos (câmaras refrigeradas e balcões térmicos) e a rotina adotada no que diz respeito à espera do alimento até a distribuição. 
Os parâmetros utilizados para verificar a conformidade das temperaturas das preparações frias expostas foram os do artigo 47 da Portaria CVS 5/2013. O artigo estabelece que os alimentos frios que apresentam temperaturas até Io$C$ devem ficar expostos por no máximo 4 horas, e os que apresentam a temperatura entre ${ }_{10}{ }^{\circ} \mathrm{C}$ e $2 \mathrm{I}^{\circ} \mathrm{C}$, por no máximo 2 horas. Os alimentos que não observarem esses critérios devem ser desprezados

\section{RESULTADOS E DISCURSÃO}

Dois tipos de saladas são servidos nas duas UANs, uma crua e outra cozida, que têm o preparo concluído às oghzomin e são servidas por volta das irhoomin, quando os refeitórios são abertos. Foram avaliadas assim, as duas preparações frias distribuídas durante 14 dias em cada UAN.

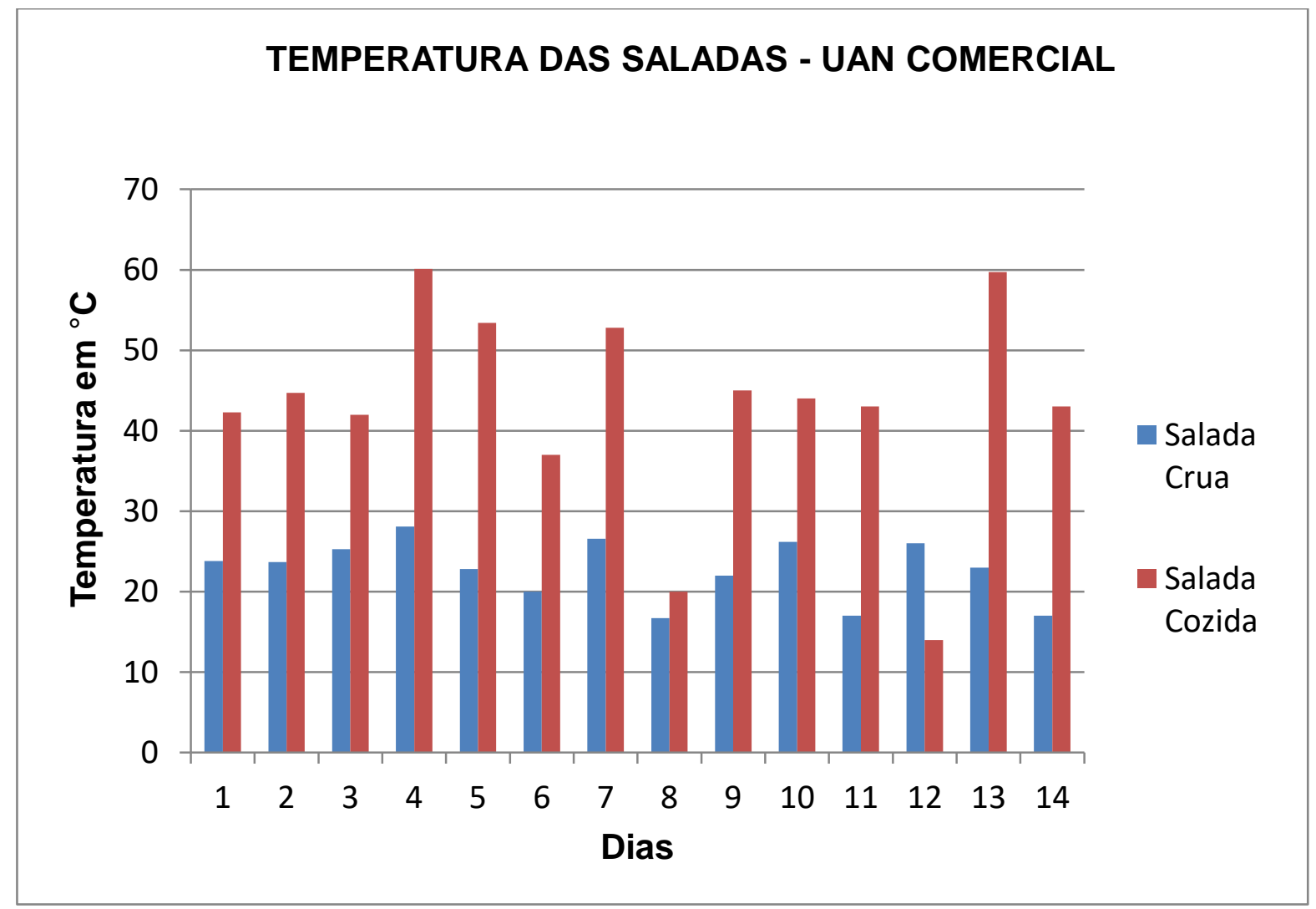

GRÁFICO I - Relação de temperaturas das amostras frias no período do almoço da UAN Comercial

Fonte: Autor. 
TEMPERATURA DAS SALADAS - UAN INSTITUCIONAL

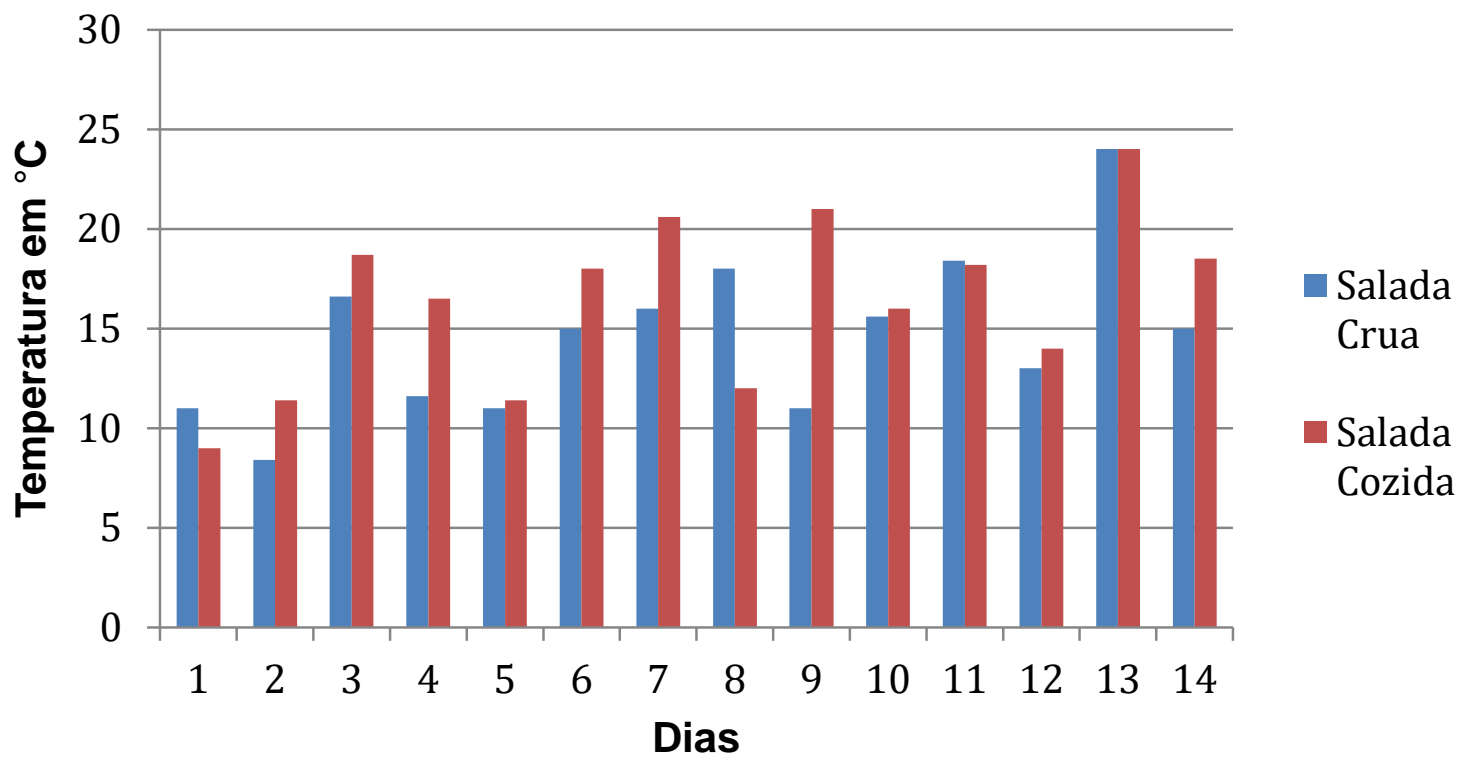

GRÁFICO 2 - Relação de temperaturas das amostras frias no período do almoço da UAN

Institucional.

\section{Fonte: Autor}

As saladas cozidas implicam em um menor risco ao considerar que passaram por um período de cocção com mais de $75^{\circ} \mathrm{C}$ e que não pode ser resfriado totalmente em 2 horas de armazenamento. No entanto, o volume das cubas deve ser observado para que o resfriamento seja atingido de forma completa. Borges (et al., 2016) enfatizou em seu estudo, que a forma de preparação e armazenamento de pratos vegetarianos analisados contribuíram para uma temperatura de armazenamento superior à verificada após o preparo no almoço, por causa da finalização ser próxima à distribuição e em grande quantidade, permanecendo armazenado em tempo insuficiente para perder calor e, consequentemente, diminuir a temperatura.

Pode-se observar na TABELA i, a média das temperaturas aferidas nas UANs, e ao apresentar um desvio padrão grande de $13 \stackrel{\circ}{\circ}$, os dados referentes às saladas cozidas da UAN comercial indicam que há uma ampla gama de valores em torno da média que é de 
42,9 @ C, enfatizando também a alta frequência da distribuição inadequada dessas preparações, mesmo com a utilização dos equipamentos de refrigeração disponíveis.

TABELA I - Média e desvio padrão das temperaturas das saladas aferidas em duas UANs distintas em I4 dias às I2hoomin

\begin{tabular}{|c|c|c|c|c|}
\hline \multirow[t]{2}{*}{ Dias } & \multicolumn{2}{|c|}{$\begin{array}{c}\text { Temperaturas em }{ }^{\circ} \mathrm{C}- \\
\text { UAN Institucional }\end{array}$} & \multicolumn{2}{|c|}{$\begin{array}{c}\text { Temperaturas em o }{ }^{\circ} \text { - } \\
\text { UAN Comercial }\end{array}$} \\
\hline & Salada Crua & Salada Cozida & Salada Crua & Salada Cozida \\
\hline $\mathrm{I}$ & II & 9 & 23,8 & 42,3 \\
\hline 2 & 8,4 & $\mathrm{II}, 4$ & 23,7 & 44,7 \\
\hline 3 & I6,6 & $\mathrm{I} 8,7$ & 25,3 & 42 \\
\hline 4 & $\mathrm{II}, 6$ & 16,5 & $28, \mathrm{I}$ & 6o,I \\
\hline 5 & II & $\mathrm{II}, 4$ & 22,8 & 53,4 \\
\hline 6 & 15 & I8 & 20 & 37 \\
\hline 7 & I6 & 20,6 & 26,6 & 52,8 \\
\hline 8 & $\mathrm{I} 8$ & 12 & I6,7 & 20 \\
\hline 9 & II & $2 \mathrm{I}$ & 22 & 45 \\
\hline IO & 15,6 & I6 & 26,2 & 44 \\
\hline II & $\mathrm{I} 8,4$ & 18,2 & $\mathrm{I} 7$ & 43 \\
\hline $\mathrm{I} 2$ & 13 & 14 & 26 & 14 \\
\hline 13 & 24 & 24 & 23 & 59,7 \\
\hline 14 & 15 & I8,5 & 17 & 43 \\
\hline Média & $14,6 \pm 4,0$ & $16,4 \pm 4,3$ & $22,7 \pm 3,8$ & $42,9 \pm 13,0$ \\
\hline
\end{tabular}

Fonte: Autor

Silva e Melo (2020) também ressalta que um fator que pode favorecer a adequação da temperatura da salada cozida é o preparo desta iniciar-se no dia anterior, sendo assim mantida por mais tempo em correta refrigeração. A salada crua apresentou maior inadequação em seu estudo, e os motivos que podem levar a essas inadequações destacouse a preparação em temperatura ambiente por muito tempo, falta de controle de ajuste da temperatura do passtrough onde ficam armazenadas após o preparo, saladas preparadas muito próximas ao horário de distribuição ou mesmo falta de equipamentos suficientes para armazenar todas as preparações. 
Nas duas UANs, as saladas preparadas são armazenadas nas câmaras frias, com temperaturas que variaram entre $4^{\circ} \mathrm{C} \mathrm{e} 14^{\circ} \mathrm{C}$, até a hora de distribuição, próximo às II:oohs, passando para o balcão térmico de $4^{\circ} \mathrm{C}$. Os Passtrhough frios não são utilizados nessas unidades, somente os quentes funcionam, o que impacta no adequado resfriamento e na correta transferência dos alimentos para a distribuição, com a menor manipulação possível. Porém, Santos e Bassi (2015) observaram que a preparação prato principal (carnes) atingiu as temperaturas preconizadas pela a legislação vigente, sendo Ioo\% adequadas. Porém as saladas também apresentaram inconformidades em suas temperaturas com $12,5 \%$ apesar de I0o\% de adequação em seus equipamentos, indicando que o tempo de exposição deve ser observado.

No restaurante comercial, as saladas são armazenadas em cubas com quantidades excessivas, por causa da grande demanda, além de excederem o período máximo de exposição à temperatura insuficiente ou ambiente. Ou seja, as preparações frias servidas abrangem um tempo de exposição de aproximadamente ozhzomin (de Irhoomin até 13h3omin), e conforme a Portaria CVS $5 / 2013$ as saladas, que apresentam mais de $10^{\circ} \mathrm{C}$ deveriam ser consumidas em até ozhoomin. Outro fator que influencia na temperatura geral desse restaurante é o ambiente, pois se trata de um local quente, apesar de possuir janelas com telas, além da alta manipulação ao servir, devido ao grande movimento de clientes. E mesmo com um balcão térmico eficiente e a espera adequada, a temperatura ideal de preparações frias não é sustentada.

Já no restaurante institucional, as saladas são armazenadas em refratários médios e em menos quantidade por se tratar de uma demanda inferior. Cada refratário fica exposto durante orhoomin cada, visto que o almoço dos funcionários se finaliza às Izhoomin. $\mathrm{O}$ refeitório é bastante ventilado, e as preparações são pouco manipuladas ao servir. Apesar da maioria das temperaturas estarem acima de ${ }^{\circ}{ }^{\circ} \mathrm{C}$, as preparações foram consideradas como adequadas de acordo a Portaria CVS 5/2013, pois permanecem no balcão de exposição até o limite de o2hoomin.

No estudo de São José (et tal 20II) as preparações frias foram detectadas com inadequações entre $50 \%$ a $65 \%$, considerando o valor inferior a $10^{\circ} \mathrm{C}$ como temperatura aceitável. Ressalta-se como solução, que a importância da disposição dos alimentos nas cubas, o tempo de exposição e a adequação das temperaturas corretas dos equipamentos de 
distribuição implicam em garantia da manutenção das preparações em condições que impeçam o desenvolvimento e multiplicação de micro-organismo. Dessa maneira, a preparação que é servida ao cliente não oferecerá qualquer risco à saúde.

\section{CONCLUSÃO}

Dos resultados expostos pode-se concluir que as Unidades de Alimentação e Nutrição (UANs) devem alinhar às suas respectivas demandas os corretos procedimentos para o controle de temperaturas. A UAN institucional obedece aos critérios do artigo $47 \mathrm{da}$ Portaria CVS 5/2013 no que diz respeito ao tempo de exposição com a temperatura inadequada. Enquanto que a UAN comercial necessita ajustar a quantidade de saladas distribuídas nas cubas e reduzir o tempo de exposição. O preparo no dia anterior das saladas cozidas também pode ser outra medida que pode auxiliar na redução das temperaturas apresentadas, além da utilização correta dos equipamentos, como os Passtrhoughs frios, a fim de melhorar o controle das temperaturas que foram encontradas fora do regulamento e evitar, consequentemente, a proliferação de microrganismos patogênicos.

\section{REFERÊNCIAS}

BARROS, N. V. dos A. et al. Avaliação da qualidade higiênico-sanitária em restaurantes selfservice do município de Picos - PI. Revista Interdisciplinar, [s. 1.], v. 12, n. 2, p. 53-6o, abr./maio/jun. 2019.

BORGES, N. R., MOURA, B. A., VIEIRA, C. F. S., SANTOS, D. D. M., ALMEIDA, L. J. \& ZUNINGA, A. D. G. Avaliação do Binômio Tempo-Temperatura das refeições de um restaurante na cidade de Palmas - TO. Desafios, 3(2), 90-98, 2016.

CONSTANCIO, M.B., AKUSTU, R.C.C.A., SILVA, ICR, CAMARGO, E.B. Revisão da Literatura - Alimentação Fora do Lar e os Desafios das Boas Práticas para a produção de alimentos de qualidade em Unidades de Alimentação e Nutrição - UAN. Acta de Ciência e Saúde. 2016; 5(2):130-143.

GUERRA, A. F. Fatores do crescimento microbiano. I $^{\text {a }}$ Edição. Rio de Janeiro: Valença; 2016.

OLIVEIRA, L. C. de; FlORES, R. R.; AMORIM, M. M. A.; FERREIRA, C. C.; AMARAL, D. A.. Avaliação das temperaturas das preparações dos restaurantes self 
service do hipocentro de Belo Horizonte/ MG. HU Revista, Juiz de Fora, v. 38, n. 3 e 4, p. 167-173, jul./dez., 2012.

PEREIRA, D.M.; PEREIRA, C.T.M, SOUSA, A.V.R. de;. Avaliação da temperatura de preparações servidas em uma Unidade de Alimentação e Nutrição. Higiene Alimentar, v. 33, n. 288-289, p. 190-194, 2019.

SÃO JOSÉ, J.F.B.; COELHO, A.I.M.; FERREIRA, K.R. Avaliação das boas práticas em unidade de alimentação e nutrição no município de Contagem-MG. Alim. Nutr., Araraquara, v.22, n.3, p.479-487, 2011.

SÃO PAULO. Secretaria da Saúde. Centro de Vigilância Sanitária. Portaria CVS 5, de 09 de abril de 2013. Aprova o regulamento técnico sobre boas práticas para estabelecimentos comerciais de alimentos e para serviços de alimentação.

SANTOS, V. N., BASSI, S. M. Avaliação da temperatura dos equipamentos e alimentos servidos em unidades de alimentação e nutrição na cidade de São Paulo. Revista Científica Linkania Master, 5(I), IIO-I25 (2015).

SIlvA, G. A.; SIlvA, L. A. da; AlVES, C. C. M.; COSTA, T. Avaliação das Temperaturas de expositores de alimentos e qualidade higiênico-sanitária em restaurante self-service, na cidade de Itapaci- GO. REFACER v. 5, n. 2, 2016.

SILVA, E. K.; MELO, C.M.T. Análise da Adequação do Binômio Tempo e Temperatura em Unidade Produtora de Refeições em Uberaba - MG. 2020. Acesso em 22/o9/2021 às 21:27 horas. https://repositorio.uniube.br/handle/123456789/1462

WIETHÖLTER, M.J.; FASSINA, P. Temperaturas de armazenamento e distribuição dos alimentos. Segurança Alimentar e Nutricional, Campinas, v.24, n.124(I):17-25, 2017. 